\title{
1 Assessing aeolian beach-surface dynamics using a remote sensing 2 approach
}

4 Irene Delgado-Fernandez ${ }^{1 *}$, Robin Davidson-Arnott ${ }^{2}$, Bernard O.Bauer ${ }^{3}$, Ian J.

5 Walker $^{4}$, Jeff Ollerhead ${ }^{5}$, Hosahng Rhew ${ }^{6}$

6

$8{ }^{1}$ Centre for Coastal \& Marine Research, School of Environmental Sciences, University of Ulster, 9 Coleraine, UK, BT52 1SA

10 2Department of Geography, University of Guelph, Guelph, ON, Canada, N1G 2W1, $11 \quad$ rdarnott@uoguelph.ca

12 '3Earth \& Environmental Sciences and Geography, University of British Columbia, Kelowna, BC, 13 Canada, V1V 1V7, bernard.bauer@ubc.ca

$14{ }^{4}$ Department of Geography, University of Victoria, Victoria, BC, Canada, V8W 3R4, 15 ijwalker@uvic.ca

$16{ }^{5}$ Department of Geography \& Environment, Mount Allison University, Sackville, NB, Canada, 17 iollerhead@mta.ca

$18{ }^{6}$ Coastal and Estuarine Morphodynamics Laboratory, Department of Oceanography, INHA

19 University, 253 YongHyun-Dong, Nam-gu, Incheon, 402-751, Korea,

20 rhew0503@hanmail.net

23 *Present address: Natural, Geographical and Applied Sciences, Edge Hill University, St. Helens 24 Road, Ormskirk, Lancashire, UK, L39 4QP, delgadoi@edgehill.ac.uk 


\section{Abstract}

27 A remote sensing technique for assessing beach surface moisture was used to 28 provide insight into beach-surface evolution during an aeolian event. An 29 experiment was carried out on October 21, 2007 at Greenwich Dunes, Prince

30 Edward Island National Park, Canada, during which cameras were mounted on a

31 mast on the foredune crest at a height of about $14 \mathrm{~m}$ above the beach. Maps of

32 beach surface moisture were created based on a calibrated relationship between

33 surface brightness from the photographs and surface moisture content measured

34 in situ at points spaced every 2.5 metres along a transect using a Delta-T

35 moisture probe. A time sequence of maps of surface moisture content captured

36 beach surface evolution through the transport event at a spatial and temporal

37 resolution that would be difficult to achieve with other sampling techniques such

38 as impedance probes. Erosion of the foreshore and berm crest resulted in an

39 increase in surface moisture content in these areas as the wetter underlying

40 sediments were exposed. Flow expansion downwind of the berm crest led to

41 sand deposition and a consequent decrease in surface moisture content. Remote

42 sensing systems such as the one presented here allow observations of the

43 combined evolution of beach surface moisture, shoreline position, and fetch

44 distances during short-term experiments and hence provide a comprehensive

45 rendering of sediment erosion and transport processes.

47 Keywords: beach surface moisture, remote sensing, aeolian geomorphology,

$48 \quad$ Greenwich Dunes 


\section{Introduction}

51 Surface moisture is an important control on the threshold of movement for

52 aeolian transport and likely on the instantaneous transport rate (Belly, 1964;

53 McKenna Neuman and Nickling, 1989; Namikas and Sherman, 1995; Cornelis

54 and Gabriels, 2003; Wiggs et al., 2004a; Davidson-Arnott et al., 2008; Nordstrom

55 et al., 2011). On beaches, surface moisture can be largely variable over time and

56 space, and it is subject to change during aeolian transport events due to local

57 erosion that exposes underlying wetter sediments or local accumulation of dry

58 sand on a previously wetted surface (e.g. Nield et al., 2011). Until recently,

59 measurements of surface moisture were acquired by taking surface scrapings or

60 cores, and returning the samples to the laboratory for gravimetric analysis. In

61 addition to the considerable labour involved and the difficulty of relating the

62 results to the true moisture content of the surface grain layer itself, this technique

63 resulted in physical disturbance of the surface through sampling and trampling.

64 The development of impedance probes such as the Delta-T Theta probe

65 (Atherton et al., 2001; Wiggs et al., 2004b; Yang and Davidson-Arnott, 2005;

66 Edwards and Namikas, 2009) allowed more frequent measurements of moisture

67 content during transport events, but such probes still have the disadvantage that

68 readings need to be taken at many points and that each measurement integrates

69 moisture over a sampling depth of about $2-6 \mathrm{~cm}$ depending on the length of the

70 probe.

71 The development of remote sensing technologies for assessing surface

72 moisture using the apparent surface brightness offers the potential to sample 
73 instantaneously over a substantial area without disturbing the surface, and this

74 approach provides a better measure of the true surface moisture content

75 (McKenna Neuman and Langston, 2006; Darke et al., 2009; Delgado-Fernandez

76 et al., 2009). Remote sensing systems have become increasingly important tools

77 in coastal research, with a number of processes and forms now being monitored

78 using Argus Systems (Holman and Stanley, 2007), satellite imagery (e.g., Wahid,

79 2008), Terrestrial Laser Scanner (TLS; Nield and Wiggs, 2011) and time-lapse

80 photography (e.g., Lynch et al., 2006; Darke et al., 2009; Delgado-Fernandez et

81 al., 2009). Summerfield (2005, p. 403) notes that it is often the introduction of

82 new techniques that stimulates 'leaps of explanatory power' and permits

83 investigation into questions previously discarded as 'incapable of being

84 addressed'. In particular, the deployment of camera systems for periods of

85 months to years has provided rich insight into the nature of aeolian transport

86 events in coastal areas (Delgado-Fernandez and Davidson-Arnott, 2011).

87 The primary purpose of this paper is to discuss the use and potential of a 88 remote-sensing camera system (Delgado-Fernandez et al., 2009) as part of a

89 short-term field experiment designed to measure wind flow and sand transport

90 across a beach foreshore and berm over a period of several hours. In this

91 application imagery was captured every 5 minutes, in contrast to the hourly data

92 collected for the meso-scale monitoring (Delgado-Fernandez, 2011). This

93 allowed detailed assessment of the evolution of surface moisture during the

94 transport event with the prospect of evaluating the effect of moisture on the

95 spatial and temporal variations in the sand transport rate. Information derived 
96 from the remotely sensed imagery was compared to data from the Theta probe in

97 order to determine the accuracy and precision of each methodology. The

98 discussion in this paper focuses on the effects of aeolian transport on surface

99 moisture content rather than moisture as a control on the threshold of aeolian

100 transport. While the latter has been widely discussed, the former can now be

101 investigated by analysing the complexities shown in moisture maps obtained

102 from the remote sensing system.

103

104 2. Study site

105 The study site was located at Greenwich Dunes, Prince Edward Island

106 (PEI), Canada (Figure 1). Greenwich Dunes are part of a barrier spit beach-dune

107 complex formed on the east side of the entrance to Saint Peter's Bay, on the

108 north shore of PEI (Mathew et al., 2010). The coast is microtidal with a mixed

109 semidiurnal regime and a maximum range at spring tides of approximately $1 \mathrm{~m}$.

110 The foredune ranges in height from 6 to $10 \mathrm{~m}$ with a stoss slope of $20-25^{\circ}$ and

111 the dune crest is aligned roughly east-west. The beach is $30-40 \mathrm{~m}$ wide and

112 consists predominantly of quartz sand with a mean diameter of $0.26 \mathrm{~mm}$. Marram

113 grass (Ammophila breviligulata) covers the foredunes and exhibits considerable

114 seasonal patterns of density and height, with individual plants typically reaching

$11525 \mathrm{~cm}$ heights. The study site was located approximately $1 \mathrm{~km}$ east of Saint

116 Peter's Bay, and covered an area of approximately $60 \mathrm{~m}$ alongshore. Further

117 information on the study site may be found in Hesp et al. (2005), Walker et al.

118 (2006), Davidson-Arnott et al. (2008) and Bauer et al. (2009). 


\section{3. Methods}

120 Wind and sand transport intensity

121 Wind and sand transport were measured using high-frequency

122 instrumentation deployed at five stations set up at $10 \mathrm{~m}$ intervals along a transect

123 oriented parallel to the wind direction from the top of the foreshore across the

124 berm crest and upper beach (Figure 2A, B). Wind direction was from the NW at

125 an angle of about $30^{\circ}$ from shore parallel. The foreshore was quite gentle with a

126 slope of $2^{\circ}$ along the transect and a height difference of about $1.2 \mathrm{~m}$ between the

127 berm crest and the low tide terrace (Figure 3B). Station 5 was set up near the

128 upper foreshore, and station 4 was located on the berm crest. Station 3 was

129 located on the gently sloping back surface of the berm crest and station 2 was

130 within a slight dip in the topography that marked the junction between the

131 landward-dipping berm slope and the seaward dipping beach surface on which

132 station 1 was located.

133 Wind flow was measured using 2-D and 3-D sonic anemometers deployed

134 on $\mathrm{H}$-frames at stations 1 to 4 (Figure 2B). Each station consisted of two Gill 3-D

135 Windmaster sonic anemometers positioned at 0.25 and $1.5 \mathrm{~m}$ above the bed,

136 and a Gill 2-D windsonic anemometer mounted at a height of $3 \mathrm{~m}$. These stations

137 were positioned at $0,10,20$ and $30 \mathrm{~m}$ along the profile (Figure 3B). An RM

138 Young cup anemometer was positioned at station 5 near the top of the foreshore

139 slope $(40 \mathrm{~m})$ at a height of $0.25 \mathrm{~m}$. A mast with a vertical array of six cup

140 anemometers was positioned near the back of the beach, but the data are not

141 utilised in this paper. 
Sand transport intensity was measured using two different sensor types:

143 'Safire' piezoelectric impact sensors (Baas, 2004; Barchyn and Hugenholtz, 2010)

144 and Wenglor laser sensors (Davidson-Arnott et al., 2009; Hugenholtz and 145 Barchyn, 2011). The Safires count only grains with sufficient momentum to 146 register when they strike the $2 \mathrm{~cm}$ sensing ring, and grains that are too small, too

147 slowly moving, or which only graze the sensor are not registered as counts. The

148 sensitivity of the sensor also varies around the circumference of the instrument,

149 particularly away from the two 'sweet spots' that mark the point of attachment of

150 the leads to the sensing ring (Baas, 2004). It has been shown that the sensitivity

151 varies from one sensor to another, and that sensitivity will vary over time

152 particularly as the rubber sheathing weathers. The five Safires deployed here

153 were selected after tests in the laboratory showed that their response to varying

154 rates of sediment discharge in an air fall column was very similar. The

155 instruments were deployed with their 'sweet spot' facing directly into the wind,

156 thus removing concerns of directionality.

157 The laser sensor (Wenglor ${ }^{\circledR}$ model YH03PCT3) consists of a laser and 158 photo sensor mounted within a $U$ shaped frame with a spacing (path length) of 3 $159 \mathrm{~cm}$ and a beam diameter of $0.6 \mathrm{~mm}$. The instrument detects the drop in voltage 160 at the photo sensor resulting from the passage of individual grains through the 161 beam. The counting circuitry is contained within the instrument and is capable of 162 detecting $>2000$ grains per second. Evaluation of the sensors indicates that they 163 count all grains (or portions of grains) above the cut-off size that pass through the 164 beam, irrespective of speed. As with all such sensors, they cannot distinguish 
165 between particles entering the beam at exactly the same time so that a few

166 particles are missed at moderate transport rates. At very large transport rates the

167 actual count may go down (Hugenholtz and Barchyn, 2011) but this only occurs

168 during very intense transport events. Transport rates here were never extreme

169 enough for the latter to be a consideration (Davidson-Arnott et al., 2009).

170 Safires were deployed at all five stations but the sensor at station 4 failed

171 early in the experiment. Wenglor laser sensors were deployed at stations 2 and 3

172 and also at a point half way between stations 1 and 2 (identified here as station

173 1.5). All sensors were sampled at $1 \mathrm{~Hz}$ over the course of the experiment.

174 Because of capacity restrictions the data logger at station 5 had to be

175 downloaded part way through the experiment resulting in a gap in data collection

176 from the anemometer and Safire at that station. There was considerable noise in

177 the data recorded by the anemometer at a height of $0.25 \mathrm{~m}$ at station 4 and,

178 while it was possible to remove some of this through filtering, the uncertainties

179 introduced into calculations of five-minute means meant that data from this

180 sensor were discarded. Finally, sand transport rates were measured using

181 vertical V traps (Nickling and McKenna Neuman, 1997) during four runs with a

182 duration of 20 minutes (run 1) and 15 minutes (runs 2-4).

184 Moisture content and image processing

185 The long-term monitoring station at Greenwich consisted of three digital

186 SLR cameras operated by a timer that triggered exposures every hour from May 1872007 to May, 2010. The cameras were deployed on top of a $6 \mathrm{~m}$ mast located on 
188 top of the $8 \mathrm{~m}$ high foredune crest (Figure 2C). The west camera had a field of 189 view of approximately $100 \mathrm{~m}$; the north camera covered a field of view of

190 approximately $40 \mathrm{~m}$ alongshore; and the east camera covered an alongshore

191 distance of $1.5 \mathrm{~km}$. The east camera provided qualitative data on beach and

192 weather conditions but the west and north cameras were used to extract

193 numerical information such as moisture maps (MM) or fetch distances (Delgado-

194 Fernandez et al., 2009). The short-term experiment described in this paper was

195 conducted over a period of about six hours on October 21, 2007 within the field of

196 view of the north camera (Figure 3A). Cameras were set to take exposures every

197 five minutes during the short-term experiment.

198 The camera images were used to obtain time series of a number of key 199 factors affecting aeolian sediment transport, such as moisture content and fetch 200 distances (Delgado-Fernandez, 2011). In particular moisture maps (MM) were 201 created by an automatic process (using Geomatica v9.1-Easi scripts) involving 202 moisture calibration, image rectification and establishment of spatial extent and 203 resolution. The process is described in detail by Delgado-Fernandez et al. (2009). 204 Moisture calibration consists of correlating surface brightness recorded by 205 digital cameras with moisture content measured at the beach surface (Darke et 206 al., 2009). Digital sampling of pixel brightness was conducted at beach locations 207 where moisture samples were collected through surface scraping. Pixel 208 brightness values were normalized against the brightness value of a 'white board' 209 in order to compensate for the effect of different environmental light in the 210 exposures due to sun angle and weather conditions. A calibration curve was 
211 obtained by plotting normalized brightness against percent moisture content

212 obtained from laboratory analysis, which allowed subsequent calculation of

213 moisture values from pixel brightness values (Delgado-Fernandez et al., 2009).

214 Image rectification transformed oblique imagery into georeferenced data by

215 matching ground control points deployed within the field of view of the cameras

216 with their corresponding map coordinates (surveyed with differential global

217 positioning system). The raster cell size of the output rectified maps was $0.05 \mathrm{~m}$

218 and was set during the process of image rectification. This was the finest

219 resolution possible given the area covered by an original pixel located in the

220 farthest position (relative to the camera) subject to rectification. Shoreline position

221 was digitized for each $\mathrm{MM}$ and vegetation cover was extracted using

222 unsupervised classifications (Delgado-Fernandez et al., 2009). This allowed

223 delimiting the beach width, which was used to establish the spatial extent of the 224 MM.

225 Finally, near-surface moisture content was measured with a Delta-T Theta 226 probe along the instrument transect at $2.5 \mathrm{~m}$ intervals. Sampling points were 227 marked with rods (Figures 2B and 3) that were visible within the images taken by 228 the camera. The probe was systematically used on the landward side of the rod, 229 which allowed subsequent comparison between moisture values obtained with 230 the Theta-probe and moisture values digitally sampled at the same locations in 231 the corresponding MM (section 4). Moisture measurements were taken before

232 runs $1-3$ and after run 4 of the trap runs, at approximately 62, 112, 190 and 242

233 minutes from the start of the experiment. The length of the stainless steel rods of 
234 the probe was shortened from the original $6 \mathrm{~cm}$ to $2 \mathrm{~cm}$ by using a $4 \mathrm{~cm}$ thick

235 dielectric foam (Yang and Davidson-Arnott, 2005).

237 4. Results

238 Spatio-temporal variations in wind flow and sediment transport intensity

239 Wind speed averaged over five-minute periods are plotted in Figure 4A 240 from the start of the experiment at 09:43 until 13:53 (250 minutes later) when

241 recording ceased for the anemometers at stations 5, 3,2 and 1 . The general

242 pattern recorded at all four stations was similar, with largest speeds recorded at

243 station 5 near the top of the foreshore slope. There was an initial increase in

244 mean speed to about $8.5 \mathrm{~ms}^{-1}$ at station 5 about 15 minutes after the start of

245 recording followed by a decrease to about $7.3 \mathrm{~ms}^{-1}$. After 60 minutes the speed

246 increased again, reaching a peak of approximately $9.5 \mathrm{~ms}^{-1}$ at about 90 minutes,

247 remaining steady at this speed until 120 minutes and then decreasing to $8 \mathrm{~ms}^{-1}$

248 by 160 minutes. The corresponding averages for transport intensity are plotted

249 for the four safires in Figure 4B and for the three Wenglor laser probes in Figure

250 4C. The temporal variations in mean sand transport intensity were somewhat

251 more complex than for winds but showed a similar pattern with a peak early in

252 the measurement period followed by a period with very low values for transport

253 intensity and then much larger values between 90 and 120 minutes. This was

254 followed by decreasing values until the end of the experiment, with the exception

255 of the Wenglor at station 3 , which showed more variability. 
The spatial pattern of wind speed across the profile can be seen more

257 clearly by comparing plots of five-minute means for five intervals (Figure 5B) that

258 are representative of the range of conditions over the recording period, with the

259 profile along the instrument line (Figure 5A). Except at the very end of the

260 recording period the wind speed pattern showed largest speeds at station 5 near

261 the top of the foreshore slope, slightly lower speeds at station 3 near the back of

262 the berm crest and a further reduction in speed at station 2 located in the shallow

263 dip of a remnant runnel at the landward end of the berm. Wind speed increased

264 slightly at station 1 on the back beach. The pattern was consistent with

265 acceleration due to flow compression as the wind traveled obliquely across the

266 foreshore slope and then a small deceleration due to flow expansion in the lee of

267 the berm crest. Unfortunately because of the problems with the lowermost sonic

268 anemometer at station 4 it was not possible to determine if there was flow

269 separation, but there is no consistent evidence for this in the records at station 3

270 and, because of the modest relief and relatively gentle apparent slope of the

271 oblique transect, it seems likely that flow remained attached over this distance.

272 The largest transport intensity measured by the safires was generally

273 found at station 3, landward of the berm crest, followed closely by the probe at

274 station 5 (Figure 5C). Smaller values were recorded at stations 1 and 2; however,

275 values for transport intensity at station 1 were almost always larger than those for

276 station 2. The largest values for the Wenglor laser sensors were also recorded at

277 station 3, with the smallest values recorded at station 2 and somewhat larger

278 values at the probe located between stations 2 and 1 (station 1.5). This shows 
279 that similar spatial patterns of sand transport intensity were recorded by these 280 two different sensor types.

$281 \quad$ Actual sand transport rates were measured using vertical integrating traps

282 that were deployed at all five stations. The trap data thus permit some evaluation

283 of transport conditions at station 4 compared to those at stations 5 and 3 (Figure

284 5D). Transport rates at station 4 on the berm crest were always larger than at

285 station 5. This pattern is to be expected if we assume that wind speed was likely

286 somewhat larger here because of flow acceleration due to flow compression up

287 the foreshore slope. Transport rates might also be expected to increase across

288 the profile with increasing fetch and decreasing surface moisture content.

289 Transport rates at station 4 were also larger than at station 3 except at the very

290 end of the experiment when wind speed had decreased considerably. At this time

291 it would be expected that the combination of light winds and larg surface moisture

292 on the foreshore slope would result in conditions that were below the threshold

293 for much of the time at this location, and transport would be largely confined to

294 entrainment of dry sand from the surface of the berm and backshore.

295

296 Spatio-temporal variations in surface moisture

297 Images of the beach were acquired every five minutes, which resulted in a

298 total of $50 \mathrm{MM}$. An examination of the moisture conditions at this frequency

299 revealed that changes were difficult to discern, and hence, 30-minute time

300 intervals were used to asses changes in surface moisture (Figure 6A). A

301 representative sample corresponding to the middle period of the experiment is 
302 shown here, from approximately 10:30 (55 $\mathrm{min})$ to 13:00 (205 $\mathrm{min})$. In addition to

303 the moisture maps themselves, difference maps were generated by subtracting

304 the data for each raster in one time period from the data for the same raster in

305 the previous time period (Figure 6B). Three classes of surface moisture change

306 were utilised: no change, drier, and wetter, with the last two classes

307 corresponding to a decrease or increase in moisture content $>2 \%$ respectively.

308 The surface at the end of the first hour was slightly damp, ranging from 2 to $6 \%$

309 moisture content. A gradual increase in near-surface wind speed from 50 to 100

310 minutes (Figure 4A) led to erosion of a surficial layer of dry sand from the

311 foreshore resulting in the west area beach surface becoming wetter at 85

312 minutes (Figure 6A). Wind speed continued to increase up to 115 minutes and

313 remained steady and relatively strong until approximately 125 minutes. MM from

31485 minutes to 145 minutes show a surface that progressively became drier on the

315 backshore (due to deposition of dry sand) but especially wetter on the foreshore

316 and west area (due to progressive erosion), as shown in the maps of changes in

317 moisture content (Figure 6B). In contrast with the first part of the experiment, the

318 foreshore became gradually dryer at 175 and especially at 205 minutes, with the

319 formation of a continuous patch of dry sediment in front of all stations. This was

320 due to a combination of sunnier conditions favouring evaporation across the

321 beach surface and relatively gentle winds not capable of eroding the newly dried

322 sand in the foreshore.

323 Moisture measurements with the Theta probe (Fig 7B) showed relatively

324 small moisture content $(5-7 \%)$ across the backshore, increasing moisture at the 
325 berm and upper foreshore (6-8\%), and the largest moisture content on the lower

326 foreshore (9-12\%). Moisture content was also re-sampled using the digital MM

327 for the same locations at two grid resolutions: $0.05 \mathrm{~m}$ (Figure $7 \mathrm{C}$ ) and $0.5 \mathrm{~m}$

328 (Figure 7D). The latter were created through a process of image coarsening,

329 which combines cells into a larger cell and averages the values of the cells

330 contained within it (Woodcock and Strahler, 1987). In the example used here,

331 each $0.5 \mathrm{~m}$ cell represents the average of $1000.05 \mathrm{~m}$ cells. The trends obtained

332 from the MM followed, in general terms, those identified with the Theta probe.

333 However the readings obtained from the coarser resolution maps (Figure 7D)

334 showed simpler trend patterns, while moisture values sampled from the finest

335 resolution maps (Figure $7 C$ ) showed unrealistically large variability. Average

336 values from the $0.5 \mathrm{~m}$ renditions were therefore adopted for the purpose of

337 comparison to the Theta probe values. Figure 8 shows a comparison of moisture

338 content values obtained from the Theta probe along the profile versus those

339 obtained from MM at $0.5 \mathrm{~m}$ grid resolution for different time intervals. In general,

340 moisture values obtained from MM presented larger variability, with both drier

341 and wetter zones than those obtained from the Theta probe. The remote sensing

342 images seem highly sensitive to slight wetting or drying of the surface while this

343 does not show up in the Theta probe results. Note that moisture readings taken

344 close to the east side of the image (e.g., $15 \mathrm{~m}$ ) at 112 minutes were greater than

345 what would be expected from a dry surface. These are currently being explored

346 as they could be a product of inaccuracies of moisture values at the edges of the 
$347 \mathrm{MM}$ or a product of slight drizzle earlier in the morning, since they are no longer

348 visible later in the day (see following section).

350 Co-evolution of surface moisture and sediment transport

351 Figure 9 shows time series for wind direction, wind speed, fetch distance,

352 moisture content obtained from the $0.5 \mathrm{~m}$ grid resolution $\mathrm{MM}$, and transport

353 intensity given by the Safires for stations $1-5$. Wind direction and speed data are

354 from the 2-D sonic at a height of $3 \mathrm{~m}$ at station 4 and are used to provide general

355 information of the incident wind field since this should be unaffected by growth of

356 the boundary layer associated with compression of flow up the foreshore slope.

357 Gaps in the moisture and fetch graphs correspond to periods of time when no

358 images were taken. Wind direction was initially very constant, from approximately

$35910^{\circ}$ to the $E$ of the instrument transect (aligned with a wind direction of $180^{\circ}$ ),

360 gradually becoming more onshore (where directly onshore is $270^{\circ}$ ) and staying at

$36120^{\circ}$ to the $\mathrm{E}$ of the instrument transect by the end of the experiment. Figure $3 \mathrm{C}$

362 shows the approximate location of the shoreline at the beginning and end of the

363 experiment, with small changes at this particular location. However, the

364 combined effect of a rising tide and gradual change in wind direction resulted in a

365 decrease of available fetch distance towards the end of the experiment,

366 especially in the landward stations because of differences in beach configuration

367 (see DEM of Figure 3A). The fetch distance decreased over the course of the

368 experiment by $9 \mathrm{~m}$ at station 5 and $22 \mathrm{~m}$ at station 1 (Figure 9). This reduced

369 fetch has significant implications for sediment transport potential across the 
370 beach and may explain, in part, why transport intensity after about 140 minutes

371 was greatly reduced (Fig 9E).

372 The beginning of the experiment was marked by cloudy conditions and 373 occasionally light drizzle, which when combined with relatively calm wind 374 conditions may have played a role in the reduction in sand transport during the 375 first hour. The drizzle ended about 50 minutes into the experiment, and soon

376 after that the clouds cleared so that evaporation due to solar radiation became a

377 factor in the reduction of surface moisture content during the latter half of the

378 experiment. Increased sediment transport during the second hour likely reflects

379 both increasing wind speed and surface evaporation. Note that while this is the

380 trend at stations 4 and 3 (Figure 9D), station 5 (closer to the foreshore) was

381 characterised by increasing surface moisture content due to progressive stripping

382 of the dry surface sediment and exposure of the wetter materials below.

383 The foreshore and lower beach were erosion zones whereas the back

384 beach was a deposition zone. At the end of the transport event, measurements 385 showed that about $5 \mathrm{~cm}$ of scour had occurred at station 5 with a smaller amount 386 at station 4 on the berm crest (Figure 10A). In contrast about $5 \mathrm{~cm}$ of deposition 387 was measured at station $3,3 \mathrm{~cm}$ at station 2, and about $1 \mathrm{~cm}$ at station 1 (Figure 388 10B). The configuration of this spatial zonation from shoreline to the foredune toe 389 became gradually aligned normal to the incoming wind direction as the event 390 progressed, with a transition zone in between strongly affected by beach 391 topography and shoreline position. The transition zone was a relatively wide area 392 (roughly around station 4) with a mixture of moist and dry conditions, and 
393 characterized by a fairly corrugated edge line resulting from transport processes

394 acting on a very complex surface due to the presence of stones, flotsam, and

395 footprints characterising the erosional surface (Figures 6 and 10C). This level of

396 complexity favours spatial approaches such as MM and remotely sensed data

397 over spot measurements along single transects such as those collected from

398 Theta-T probes, which do not provide enough detail on spatial textures.

\section{5. Discussion}

401 Comparison of Theta-T and MM moisture values raise a number of 402 questions regarding the assessment of surface moisture content as a primary 403 control on aeolian sediment transport. Values from MM of $0.5 \mathrm{~m}$ resolution 404 showed a better correlation with the Theta-T probe values, which are reliable 405 indicators of surface moisture content when there are smooth transitions in 406 moisture gradients along a given beach transect. Values from $\mathrm{MM}$ at $0.05 \mathrm{~m}$

407 resolution contain a large degree of variability in moisture readings, and the 408 question is whether such variation is 'noise' or a true representation of the nature 409 of the evolving beach surface during a transport event. When transport was 410 active, there were discrete zones of dry sand that were being deposited beside a 411 moist transport surface that was recently eroded. For example, Figure 2B shows 412 a complex surface with moisture patches alongside dry sand as a result of active 413 aeolian streamers and deposition/erosion processes. In this instance, the MM 414 appear to be yielding 'noisy' but detailed information that may be representative 415 of the complex evolution of the beach surface through time. Further analysis is 
416 being undertaken to investigate these micro-scale complexities and to assess the

417 accuracy of moisture data at the edges of MM.

418 A related issue has to do with quantifying a characteristic moisture value

419 that should be used in explanations of sediment transport as a function of wind, 420 moisture, and fetch distances. The $0.05 \mathrm{~m}$ resolution MM provide detailed

421 representations of beach surface moisture but sediment transport rates might 422 correlate better with averaged moisture values over a given area. Furthermore, 423 transport rates could be better explained using some measure of the spatial 424 distribution of moisture values over a set distance (e.g., $1 \mathrm{~m}, 2 \mathrm{~m}$, or $10 \mathrm{~m}$ ) in 425 front of a given trap. MM provide an excellent platform for these types of 426 investigations because they allow analysis of moisture content at different spatial 427 resolutions.

428 In addition to providing a measure of the actual moisture content of the 429 upper-most sand grain layer, in contrast to the depth-averaged sample (from 1.5-

$4306 \mathrm{~cm}$ thickness) from the Theta probe (Atherton et al., 2001; Yang and Davidson431 Arnott, 2005; Schmutz and Namikas, 2011), the process of cell aggregation of 432 fine resolution $(0.05 \mathrm{~m}) \mathrm{MM}$ into coarser resolution $(0.5 \mathrm{~m}) \mathrm{MM}$ offers the 433 advantage of providing more representative spatially-average values. Detailed 434 sampling of surfaces with moderate moisture content using the Theta probe have 435 shown that there can be a large degree of variability within an area as small as 1 $436 \mathrm{~m}^{2}$ (Yang and Davidson-Arnott, 2005; Edwards and Namikas, 2009). While Theta

437 probes provide point measurements that are assumed to be representative of a 438 given area, a cell from the coarse resolution MM presented here would represent 
439 the average of 100 moisture measurements over an area of $0.5 \mathrm{~m}^{2}$. Taking a

440 similar size sample with a Theta probe would be intrusive and obviously highly

441 time consuming.

442 While surface moisture is an important control on aeolian transport (Belly,

443 1964; McKenna Neuman and Nickling, 1989; Namikas and Sherman, 1995;

444 Cornelis and Gabriels, 2003; Wiggs et al., 2004b; Davidson-Arnott et al., 2008)

445 results from this study demonstrate that transport is in turn an important control

446 on surface moisture content as the beach surface evolves through localized

447 erosion and deposition. Surface moisture is related to transport in two opposing

448 ways. Safires at stations 5 (foreshore) and 3 (back beach) recorded a peak of

449 transport intensity from approximately 80 to 120 minutes, coinciding with the

450 increase of wind speed. However, surficial moisture content increased at station

4515 but decreased at station 3 (Figure 9). The combination of flow acceleration up

452 the foreshore slope and a short fetch (no sediment source upwind) transformed

453 the foreshore (station 5) into an erosive zone. Hence, relatively large values for

454 moisture content at this location were the result of sediment erosion and

455 landward transport. This is in line with observations on sediment transport

456 dynamics on a drying beach by Nield et al. (2011) who reported erosion of dry

457 sediment leading to an increase of surface moisture due to the exposure of the

458 underlying, wetter surface. Large transport rates at station 3 (back beach) were

459 associated with significant accumulation of dry sand and hence small values of

460 surface moisture content. Details of the temporal evolution of moisture content in

461 these two different zones reveal complex feedbacks between moisture, wind 
462 speed, sand transport, and fetch distances where moisture is not only a control

463 for sediment movement but also a result of patterns of erosion and accumulation.

464 The largest transport rates at stations 5 and 3 were recorded during the first trap

465 run (96 minutes; Figure 5D), coinciding with the strongest wind speeds and the

466 peak of saltation recorded by the Safires (Figure 9). As suggested by the MM

467 (Figure 6A) most of the sand collected during this run at station 5 was the result

468 of the erosion of a relatively dry layer from the foreshore, which in turn increased

469 the surface moisture content there. Transport rates at station 5 during the second

470 run (127 minutes) were smaller than at station 1 (Figure 5D) despite strong winds

471 of $9-9.5 \mathrm{~ms}^{-1}$ similar to those recorded during run 1 . Hence the erosion of the

472 layer of dry sediment from this zone during run 1 produced larger levels of

473 surface moisture during run 2, which in turn limited further erosion. At stations 3-

474 1, dry sediment stripped from the foreshore was deposited progressively leading

475 to drier surface sediment. These deposits are easily mobilized under stronger

476 wind conditions, but boundary layer evolution leads to reduced surface shear

477 stress and hence, deposition toward the toe of the dune.

\section{6. Conclusion}

480 This paper demonstrates the applicability of a remote sensing system to 481 measuring beach surface moisture over a short-term experiment. The detailed 482 temporal and spatial resolution of the evolution of surface moisture provided by 483 the time-lapse photography provides an improved explanation for the spatial and 484 temporal patterns of sand transport, and the changes in the beach surface 
485 resulting from scour and deposition. The conclusions can be summarised as 486 follows:

487 1) Spatial patterns of erosion, transport and deposition over the foreshore 488 and berm reflect the changing boundary layer produced by flow 489 compression up the foreshore slope and then expansion over the reverse $490 \quad$ slope on the landward side of the berm;

4912 2) Temporal patterns of sand transport intensity reflect both changes in wind 492 speed and direction (fetch distance) over the event, upwind sources of 493 available dry sediment, and the effects of changes in surface moisture;

494 3) Fine resolution moisture maps offer the possibility of data aggregation 495 through pixel coarsening and may be used to explore appropriate moisture $496 \quad$ values for different applications. While averaged moisture values obtained from coarser resolution $(0.5 \mathrm{~m}) \mathrm{MM}$ were more similar to those obtained with the Theta probe these may be smoothing out important micro-scale information. Further research should be conducted to determine the appropriate temporal and spatial resolution of moisture measurements.

4) The high resolution of the surface MM permits the identification of changes in moisture over the whole surface that reflect external conditions such as solar radiation input and precipitation as well as internal conditions produced by the erosion (wetting) and deposition (drying) of sand.

5) The remote sensing system thus provides a relatively simple approach to 506 measuring the evolution of the beach surface during a transport event, and 

to providing more comprehensive explanations of processes of erosion

$508 \quad$ and transport and changes in surface conditions.

\section{Acknowledgements}

511 We thank Parks Canada for granting permission to carry out work at Greenwich

512 Dunes and personnel at Greenwich Dunes for their support in the field, especially

513 Kirby Tulk, Allan Doyle, Tarah McFee, Roger Steadman, and Miguel Santos.

514 Rosie Smith conducted the DGPS surveys, Mario Finoro and Sandy McLean

515 provided technical support with building and testing equipment, and Adam

516 Bonnycastle aided in the development of scripts. Financial support was provided

517 through a Natural Sciences and Engineering Research Council of Canada

518 Discovery Grant to RD-A, through a research grant from Parks Canada to RD-A,

519 IJW and JO, and through the Ontario Graduate Scholarship Program and

520 University of Guelph Lattornell Travel grant to ID-F.

\section{References}

523 Atherton R.J, Baird, AJ, Wiggs GFS. 2001. Inter-tidal dynamics of surface 524 moisture content on a meso-tidal beach. Journal of Coastal Research 17 : $525 \quad 482-489$.

526 Baas AC W. 2004. Evaluation of saltation flux impact responders (Safires) for 527 measuring instantaneous aeolian sand transport intensity. Geomorphology $528 \quad 59: 99-118$. 
529 Barchyn TE, Hugenholtz CH. 2010. Field comparison of four piezoelectric 530 sensors for detecting aeolian sediment transport. Geomorphology 120 : $531 \quad 368-371$.

532 Bauer BO, Davidson-Arnott RGD, Hesp PA, Namikas SL, Ollerhead J, Walker IJ. 2009. Aeolian sediment transport on a beach: surface moisture, wind fetch, and mean transport. Geomorphology $105: 106-116$.

535 Belly PY. 1964. Sand movement by wind. U.S. Army Corps of Engineers CERC, $536 \quad$ Tech. Memo. $1: 38 \mathrm{pp}$.

537 Cornelis WM, Gabriels D. 2003. The effect of surface moisture on the 538 entrainment of dune sand by wind: an evaluation of selected models. $539 \quad$ Sedimentology $50: 771-790$.

540 Darke I, Davidson-Arnott RGD, Ollerhead J. 2009. Measurement of Beach $541 \quad$ Surface Moisture Using Surface Brightness. Journal of Coastal Research $542 \quad 26: 248-256$.

543 Davidson-Arnott RGD, Yang Y, Ollerhead J, Hesp PA, Walker IJ. 2008. The 544 effects of surface moisture on aeolian sediment transport threshold and 545 mass flux on a beach. Earth Surface Processes and Landforms 33 : 55-74.

546 Davidson-Arnott RGD, Bauer BO, Walker IJ, Hesp PA, Ollerhead J, Delgado$547 \quad$ Fernández I. 2009. Instantaneous and mean aeolian sediment transport 548 rate on beaches: an intercomparison of measurements from several 549 sensor types. Journal of Coastal Research, SI 56, 297-301. 
550 Delgado-Fernandez I, Davidson-Arnott RGD, Ollerhead J. 2009. Application of a remote sensing technique to the study of coastal dunes. Journal of Coastal Research $25: 1160-1167$.

553 Delgado-Fernandez I. 2011. Meso-scale modelling of aeolian sediment input to coastal dunes. Geomorphology $130: 230-243$.

555 Delgado-Fernandez I, Davidson-Arnott RGD. 2011. Meso-scale aeolian sediment input to coastal dunes: The nature of Aeolian transport events. Geomorphology $126: 217-232$

558 Edwards BL, Namikas SL. 2009. Small-scale variability in surface moisture on a fine-grained beach: implications for modeling aeolian transport. Earth Surface Processes and Landforms 34 : 1333-1338.

561 Hesp PA, Davidson-Arnott RGD, Walker IJ, Ollerhead J. 2005. Flow dynamics over a foredune at Prince Edward Island, Canada. Geomorphology 65 :

564 Holman RA, Stanley J. 2007. The history and technical capabilities of Argus. $565 \quad$ Coastal Engeenering Reseach Centre $54:$ 477-491.

566 Hugenholtz $\mathrm{CH}$, Barchyn TE. 2011. Laboratory and field performance of a laser 567 particle counter for measuring aeolian sand transport. Journal of $568 \quad$ Geophysical Research. 116 : F01010, 13 pp. doi:10.1029/2010JF001822

569 Lynch K, Jackson DWT, Cooper AG. 2006. A remote-sensing technique for the $570 \quad$ indentification of aeolian fetch distance. Sedimentology $53: 1381-1390$.

571 Mathew S, Davidson-Arnott RGD, Ollerhead J. 2010. Evolution of a beach-dune 572 system following a catastrophic storm overwash event: Greenwich Dunes, 

$: 1-18$

575 McKenna Neuman C, Nickling WG. 1989. A theoretical and wind tunnel 576 investigation of the effects of capillary water on the entrainment of sediment by wind. Canadian Journal of Soil Science $69:$ 79-96.

578 McKenna Neuman C, Langston G. 2006. Measurement of water content as a 579 control of particle entrainment by wind. Earth Surface Processes and $580 \quad$ Landforms $31: 303-317$.

581 Namikas SL, Sherman DJ. 1995. A review of the effects of surface moisture 582 content on aeolian sand transport. Desert Aeolian Processes. V. P. Tchakerian. London, Chapman and Hall Ltd : 269-293.

584 Nickling WG, McKenna Neuman C. 1997. Wind tunnel evaluation of a wedgeshaped aeolian transport trap. Geomorphology $18: 333-345$.

586 Nield JM, Wiggs GFS. 2011. The application of terrestrial laser scanning to aeolian saltation cloud measurement and its response to changing surface moisture. Earth Surface Processes and Landforms 36 : 273-278.

Nield JM, Wiggs GFS, Squirrell RS. 2011. Aeolian sand strip mobility and protodune development on a drying beach: examining surface moisture and surface roughness patterns measured by terrestrial laser scanning.

593 Nordstrom KF, Jackson NL, Korotky KH, Puleo JA. 2011. Aeolian transport rates 594 across raked and unraked beaches on a developed coast. Earth Surface Processes and Landforms $36: 779-789$. 
596 Schmutz PP, Namikas SL. 2011. Utility of Delta-T Theta probe for obtaining surface moisture measurements from beaches. Journal of Coastal Research 27 : 478-484.

599 Summerfield MA. 2005. The changing landscape of geomorphology. Earth $600 \quad$ Surface Processes and Landforms $30: 779-81$.

601 Wahid AM. 2008. GIS-Based Modeling of Wind-Transported Sand on the Qaa 602 Plain Beach .Southwestern Sinai. Egypt. Journal of Coastal Research 24 : $603 \quad 936-943$.

604 Walker IJ, Hesp PA, Davidson-Arnott RGD, Ollerhead J. 2006. Topographic 605 Steering of Alongshore Airflow over a Vegetated Foredune: Greenwich Dunes, Prince Edward Island, Canada. Journal of Coastal Research 22 : 1278-1291. the entrainment and transport of sand by wind. Geomorphology 59 : 13-30.

610 Wiggs GFS, Atherton RJ, Baird AJ. 2004b. Thresholds of aeolian sand transport: 611 establishing suitable values. Sedimentology $51: 95-108$.

612 Woodcock CE, Strahler AH. 1987. The factor of scale in remote sensing. Remote $613 \quad$ Sensing of Environment $21: 311-332$.

614 Yang Y, Davidson-Arnott RGD. 2005. Rapid measurement of surface moisture 615 content on a beach. Journal of Coastal Research $21: 447-452$. 
619 List of Figures

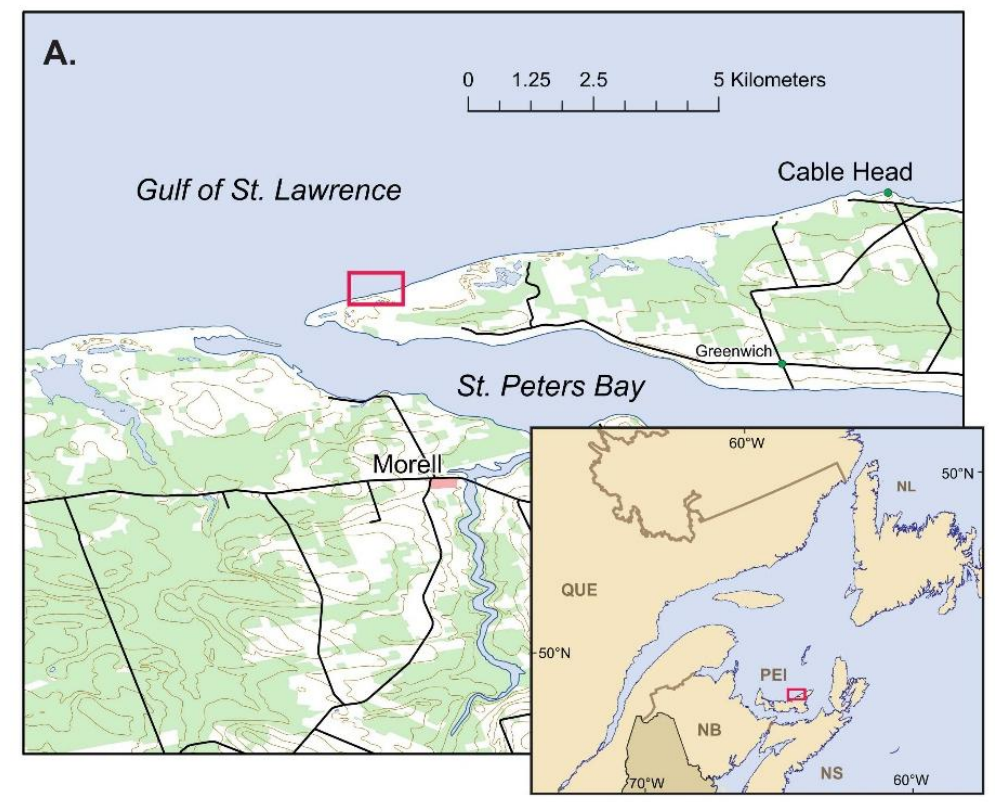

Figure 1: Location of study site at Greenwich Dunes, Prince Edward Island (Canada).

620 


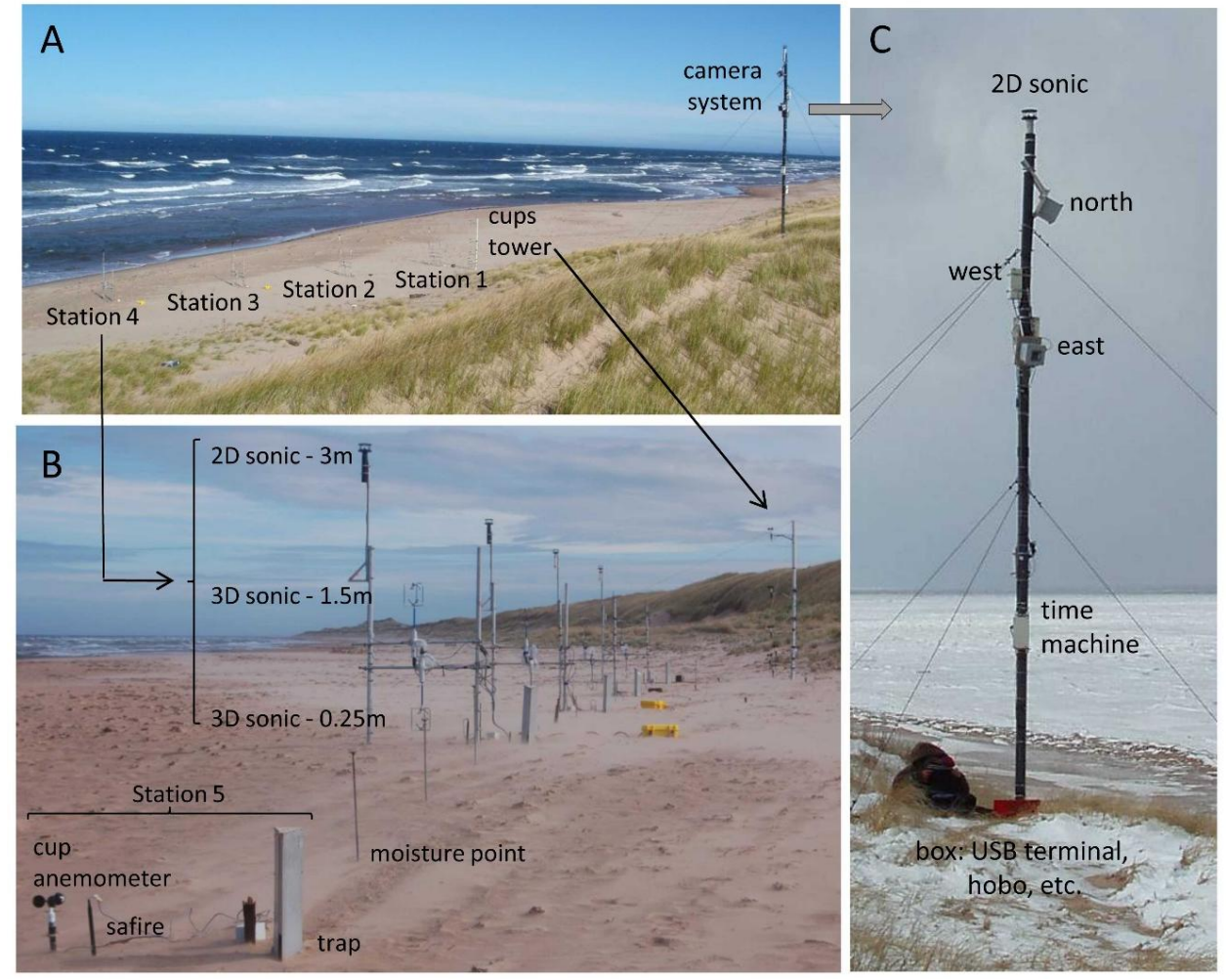

Figure 2: A) General view of study site and instruments; B) close-up of instruments setup. The transect consisted of four stations, each with one 2D and two 3D sonic anemometers located at $3,1.5$, and $0.25 \mathrm{~m}$ over the beach surface, and one station with a cup anemometer at $0.25 \mathrm{~m}$ over the beach surface. Traps and safires were co-located at each of the stations and moisture points selected every $2.5 \mathrm{~m}$. The transect ran into the incoming wind direction (oblique onshore) and ended in a tower of cup anemometers close to station $1 ;$ C) close-up of camera system. 

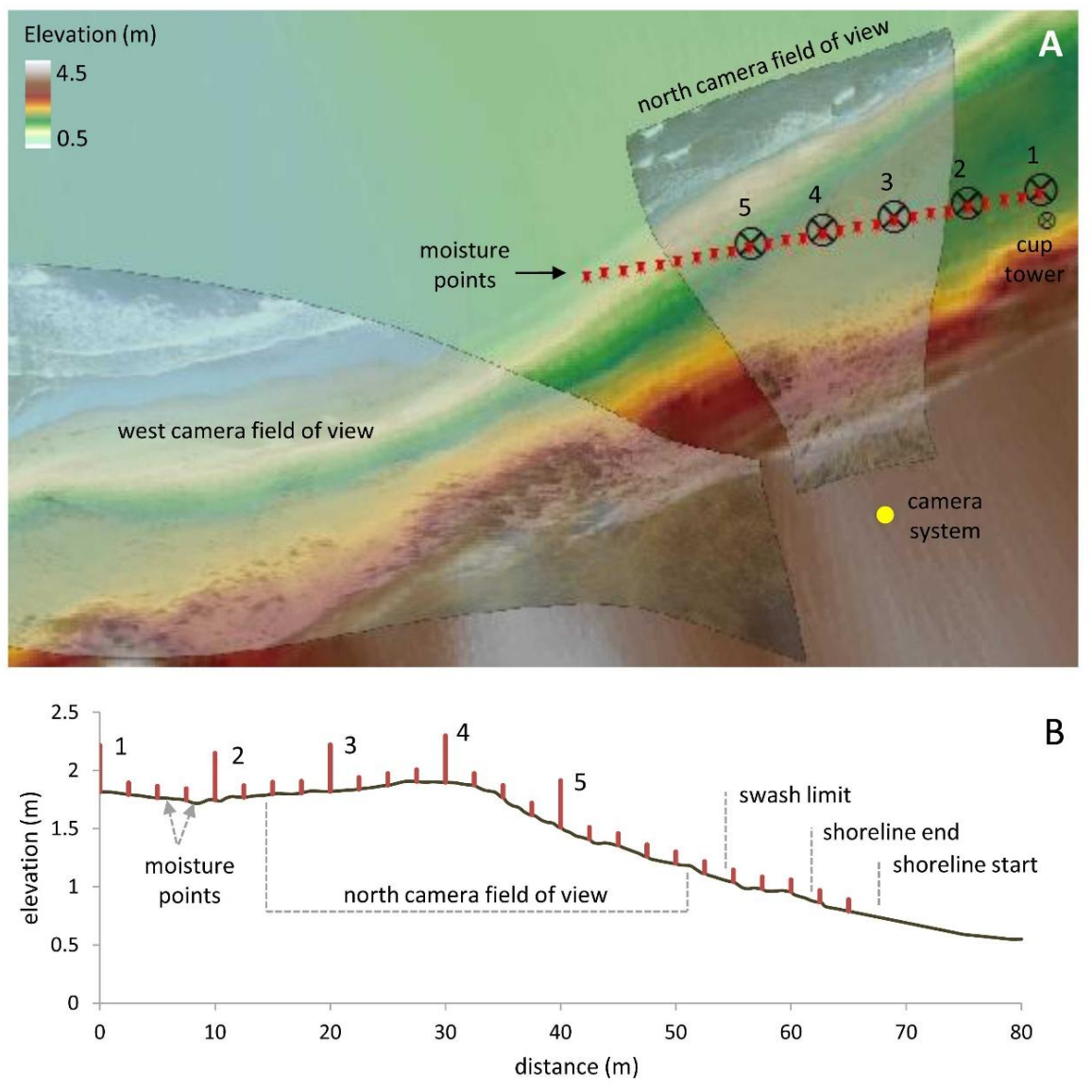

Figure 3: A) Digital elevation model (DEM) georectified from $1 \mathrm{~m}$ spot resolution differential global positioning system (DGPS) data. Topographic data was gathered on the beach surface and up to the dune toe and thus the DEM does not include the dune. The position of each station is marked with the station number. Stations $3-5$ and a total of 15 moisture points were within the north camera field of view (inserted as a semi-transparent image); B) topographic profile along the instruments transect, showing the approximate location of the shoreline position at the beginning (shoreline start) and end of the experiment. 
A.

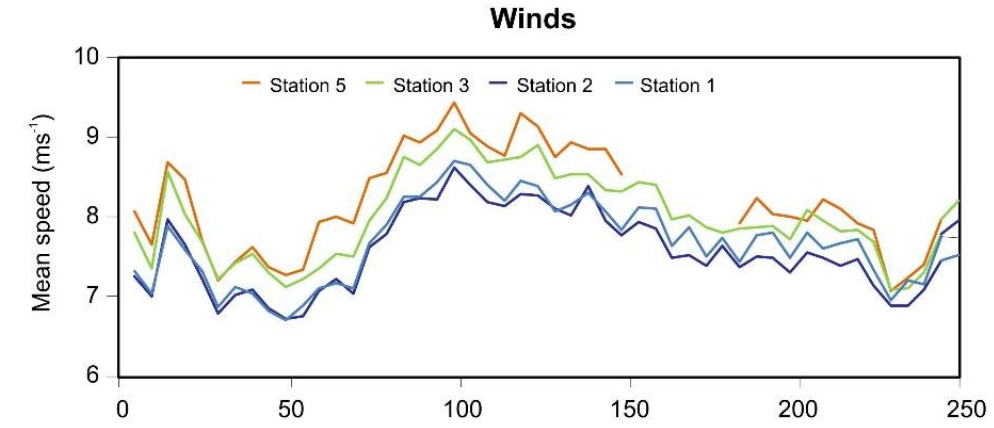

B.

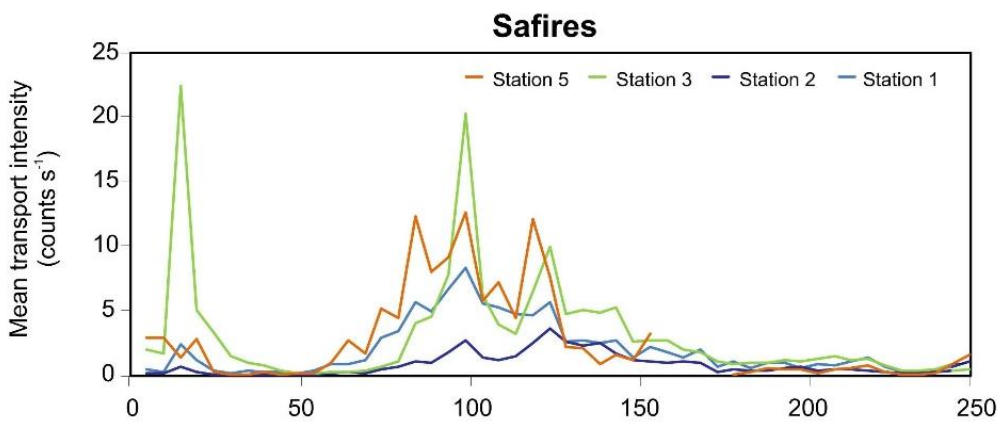

C.

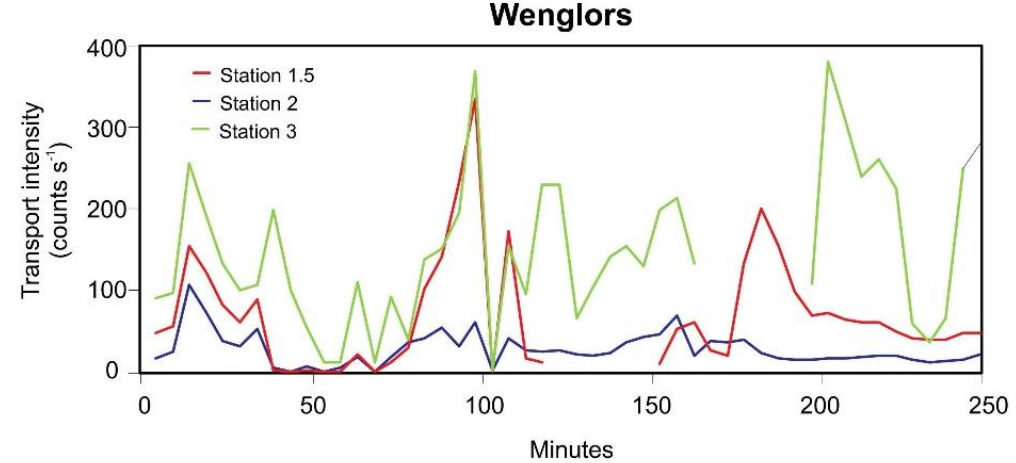

Figure 4: Temporal variations in wind speed and sediment transport intensity. A) five-minute averages for wind speed $\left(\mathrm{ms}^{-1}\right)$ measured at stations 1, 2, 3 and 5 at $0.25 \mathrm{~m}$ height; B) average saltation intensity (counts $\mathrm{s}^{-1}$ ) measured by Safire probes at the same stations; C) average saltation intensity (counts $\mathrm{s}^{-1}$ ) measured by Wenglor laser sensors at stations 2, 3 and midway between 1 and 2 . Note that the grain counts measured by the Wenglors are much larger than those measured by the Safires (see Davidson-Arnott et al., 2009). 
A.

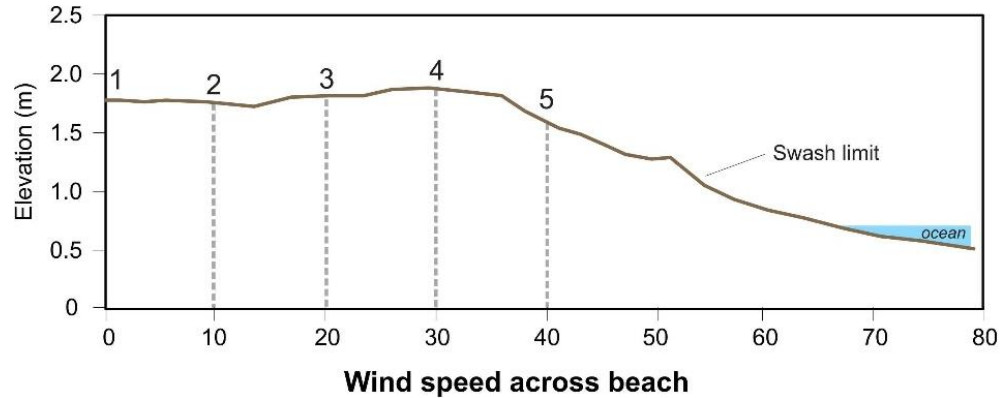

B.

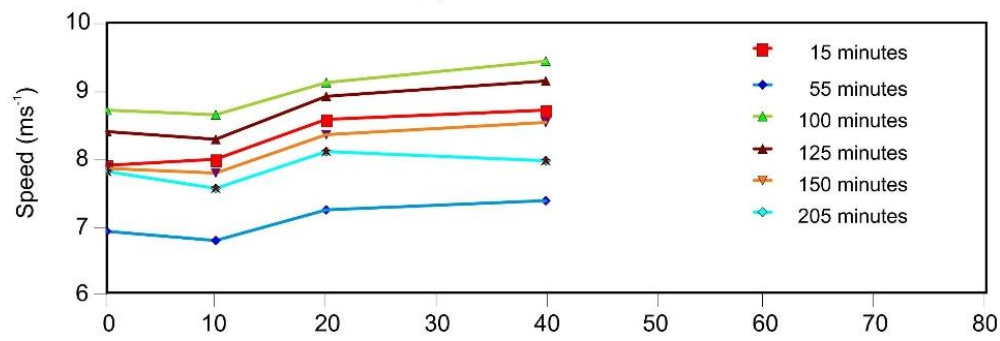

C.

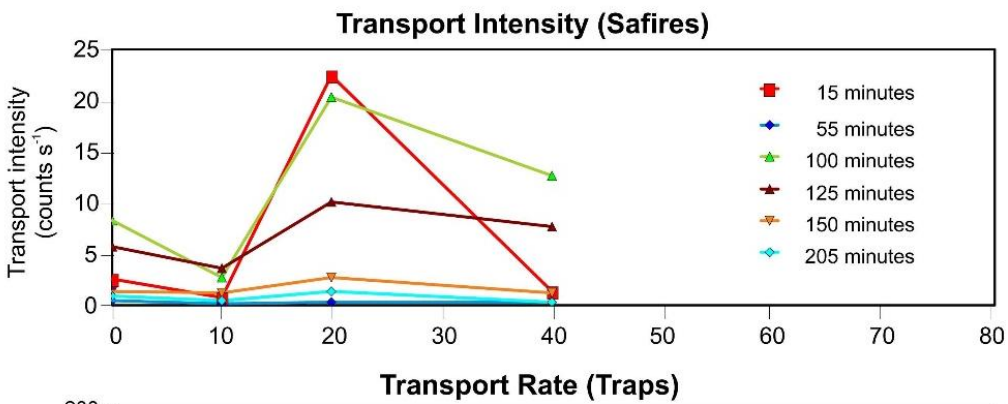

D.

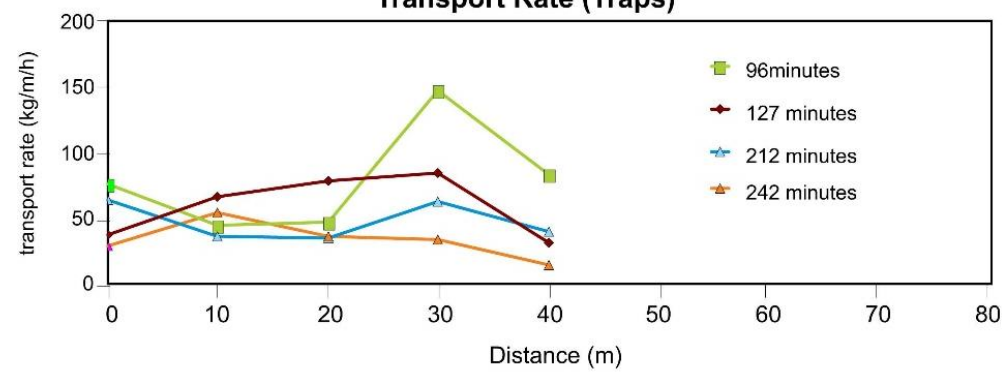

Figure 5: Spatial pattern of winds and sediment transport. A) beach profile along instruments transect; B) mean wind speeds for 6 five minute periods; C) transport intensity measured by the Safire probes for the same 5 minute periods as B); D) transport rate measured by vertical traps. Run 1 had a duration of 20 minutes and the other thre runs a duration of 15 minutes. Times are for the end of the run. 


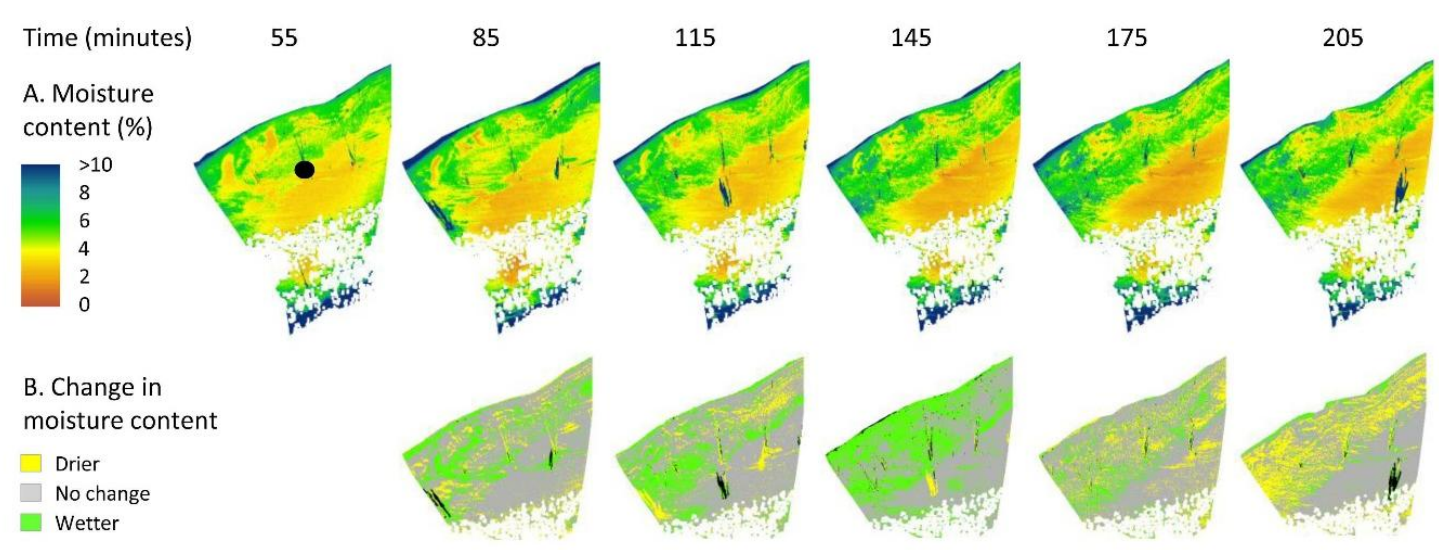

Figure 6: Temporal variations in moisture content. A) temporal sequence of moisture maps every 30 minutes; B) maps showing the change in moisture content relative to the previous moisture map. Only relative changes over $+/-2 \%$ have been considered, with drier areas (change $>2 \%$ ) shown in orange and wetter areas (changes $>-2 \%$ ) in green. The black dot shows the location of station 4. 

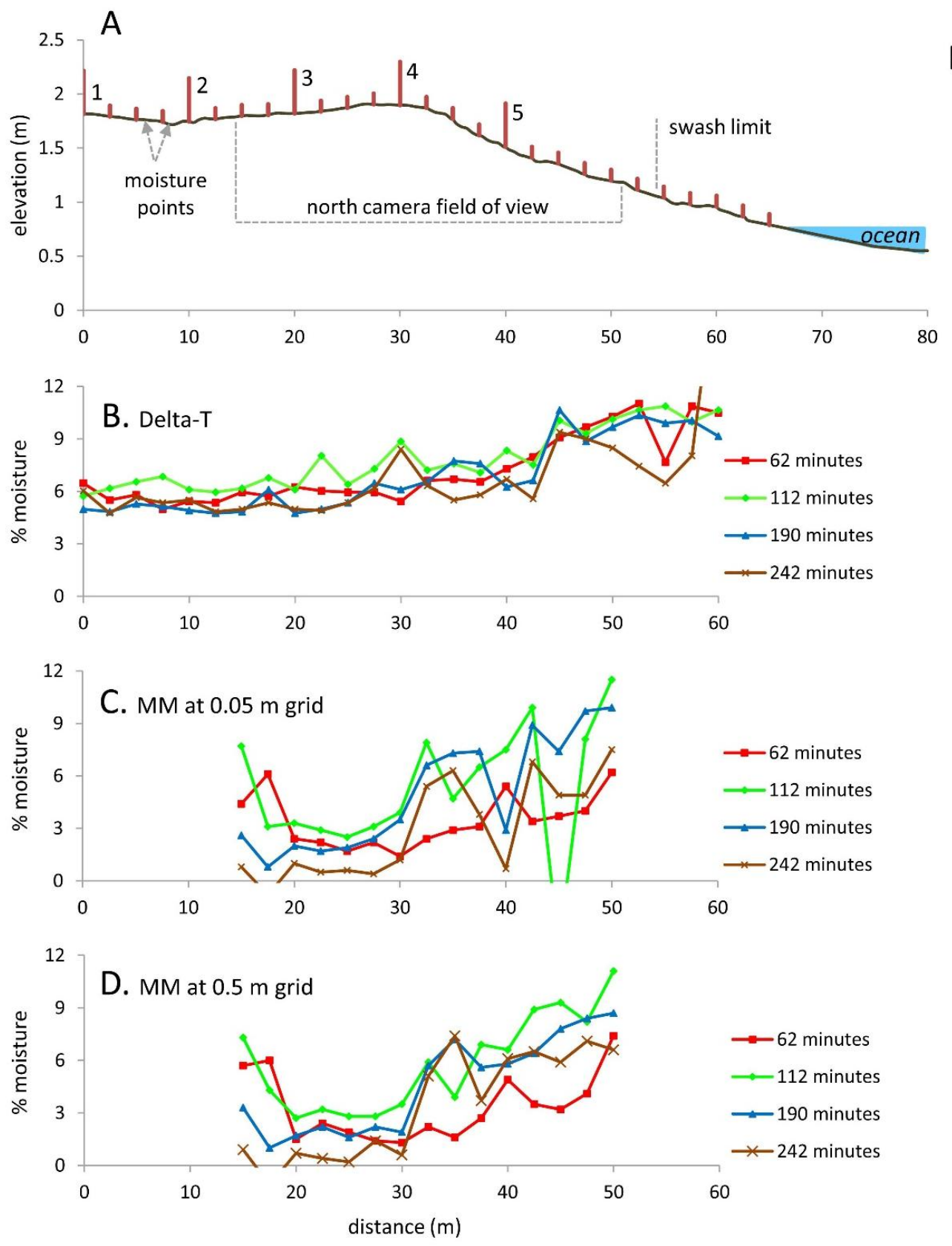

Figure 7: A) Beach profile along the instruments transect; B) Measurements of near surface moisture (upper $2 \mathrm{~cm}$ ) taken at four times along the instrument profile using the Delta-T Theta Probe; C) Surface moisture at the same four times and locations (within the field of view of the camera) estimated from moisture maps at the original grid resolution of $0.05 \mathrm{~m}$; D) Measurements of surface 
moisture from moisture maps at a coarser resolution of $0.5 \mathrm{~m}$.

626
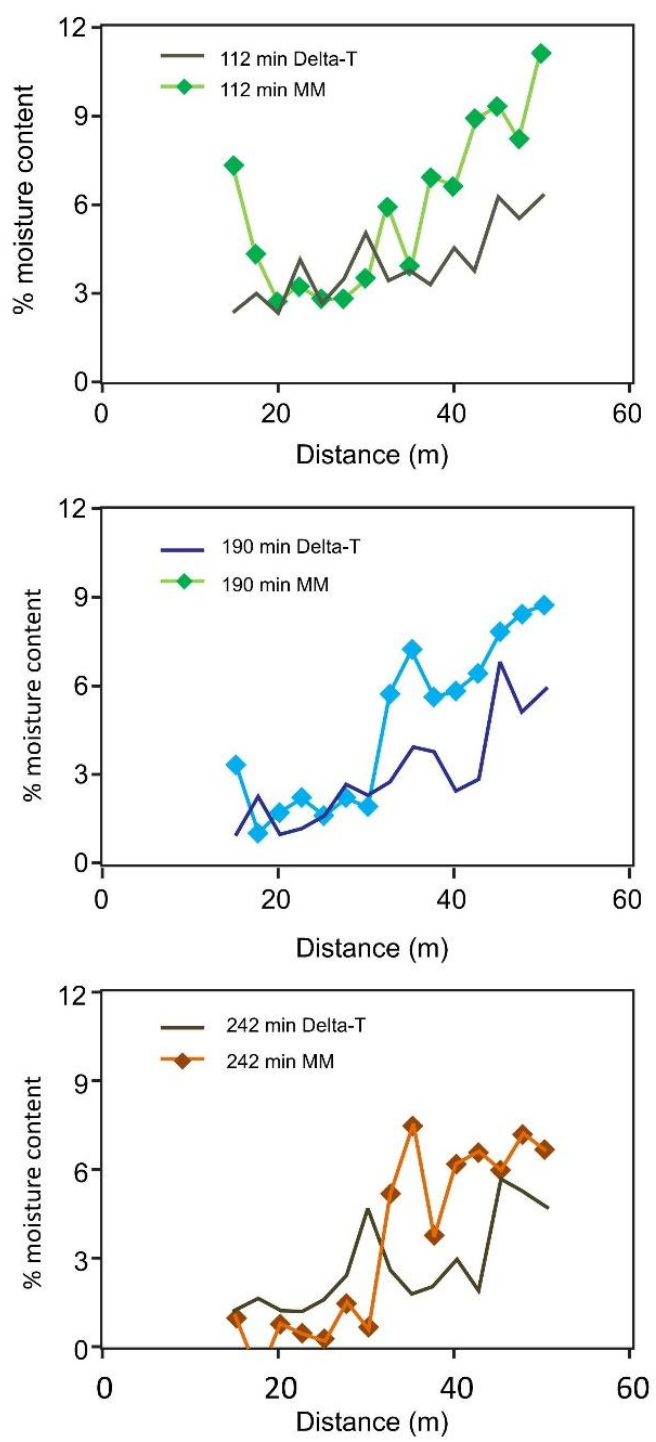

Figure 8: Plot of moisture values from the Delta-T Theta probe and moisture maps (MM) at $0.5 \mathrm{~m}$ grid resolution at three different time intervals. In general terms, the MM values show a larger variability of moisture values and sharper differences between the wettest and driest ends. 

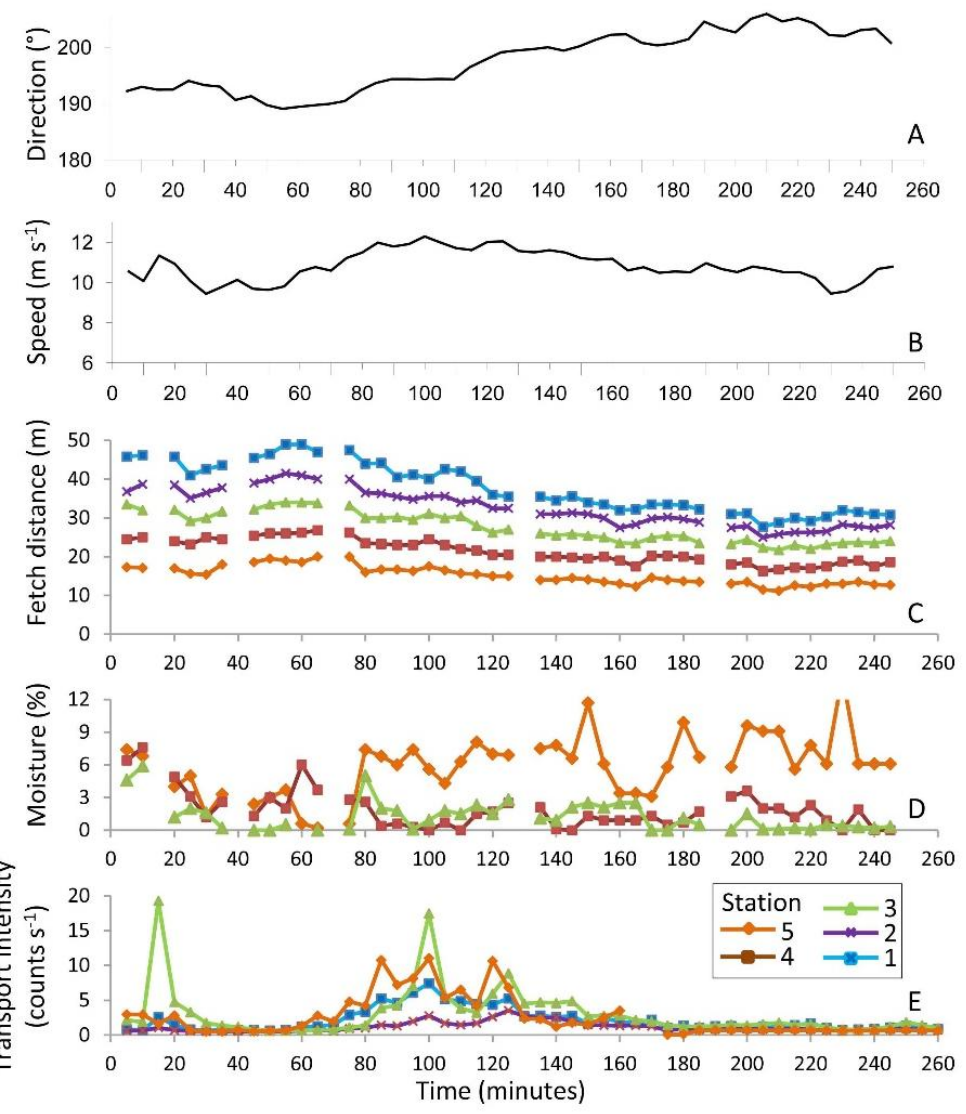

Figure 9: Five minute averages for incident wind direction $(A)$ and wind speed (B) recorded at $3 \mathrm{~m}$ high over the beach surface at station 4 , fetch distances $(C)$, surface moisture content for stations 3-5 (within the field of view of the camera; D), and sediment transport intensity (E). Gaps in the data correspond to periods of time when no images were taken. 

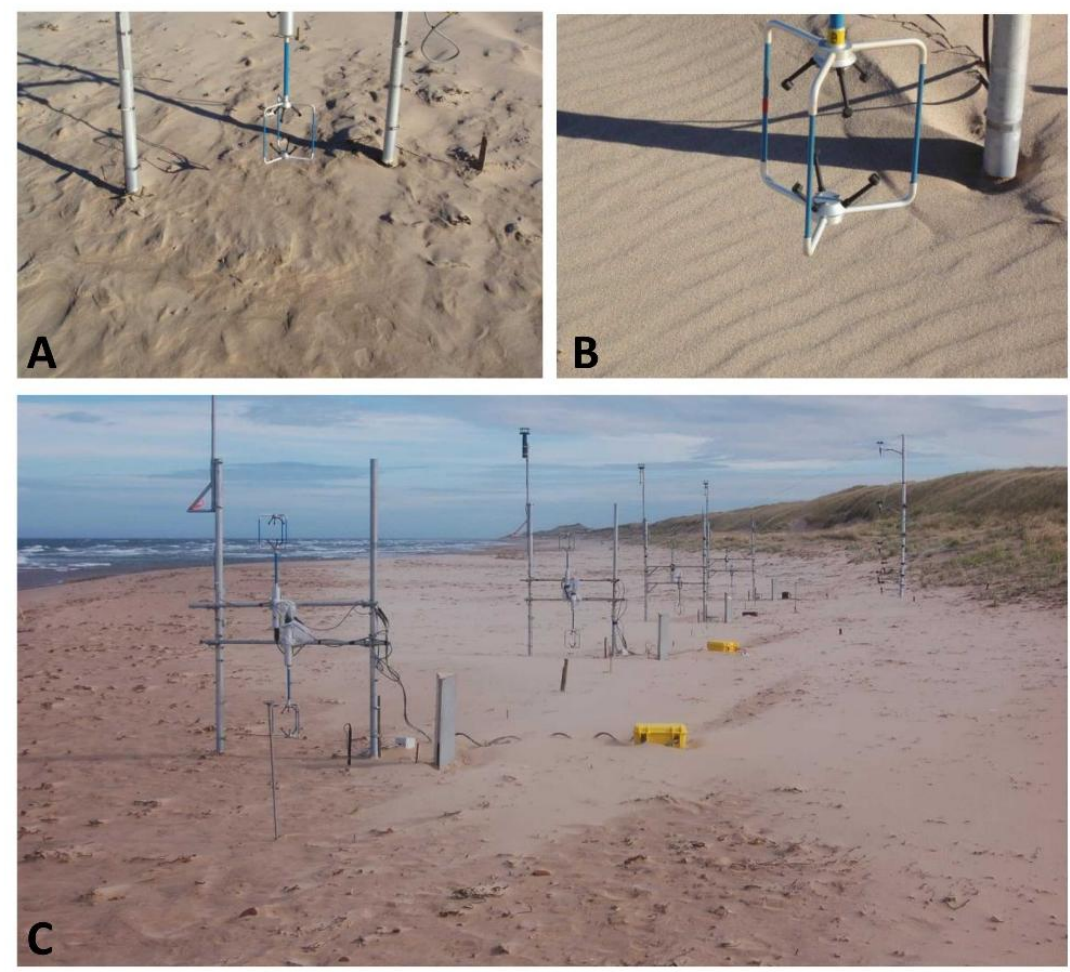

Figure 10: Photographs of the beach surface at the end of the transport event: A) close-up of station 4; B) ripples formed in the dry sand accumulation at station 2; C) view of station 4 looking landward showing the eroded and relatively damp surface with a transition to deposition towards station 3 in the background. 